\title{
Psychological Impact of Male Breast Disorders: Literature Review and Survey Results
}

\author{
Mike Kipling Jane E.M. Ralph Keith Callanan \\ Breast Unit, University Hospital of North Durham (UHND), Durham, UK
}

\section{Keywords}

Male breast cancer - Cancer - Anxiety

\section{Summary}

Background: Referrals of men to breast assessment clinics are increasing. While most of the men will have benign disease, some of them will have breast cancer. Whichever pathology they have, men should be offered a service tailored to their needs, rather than being 'shoehorned' into a service designed to care for women. This paper explores the psychological impact on men of their condition and of attending a breast assessment clinic. Methods: The literature regarding male experience of breast problems is reviewed, and screening for psychological morbidity is discussed. Results of a survey regarding an all-male breast assessment clinic are reported, with a plan for future research. Results: Many of the 78 men surveyed described negative feelings relating to their condition although they did not want to be seen in an all-male breast assessment clinic if that meant a longer wait. Men reported feelings of anxiety, embarrassment, emasculation and even depression regarding their condition. Conclusions: Men are distressed by gynaecomastia and need psychological support for any breast-related presentation. More formalised research into this area is needed, although the men's distress does not translate into the desire to attend an all-male assessment clinic if this means a longer wait before being seen.

\section{Introduction}

In line with other surgical oncology specialties, the emphasis for breast services is the diagnosis and treatment of malignant disease. However, the majority of patients assessed will have benign breast disease. $80 \%$ of men attending a breast assessment clinic will have gynaecomastia [1]. Although male breast cancer $(\mathrm{MBC})$ is rare, the number of men being re- ferred for breast assessment is increasing (table 1), prompting a need to streamline and optimise clinical pathways. This rise coincided with the introduction of the '2-week rule for everybody' policy for breast referrals in 2009 in the United Kingdom. With increasing numbers of men being seen, there is a call to recognise not only the more obvious biological aspects but also the subtler psychological and social aspects of male breast problems, and for research and awareness in this field [1].

\section{Male Breast Cancer}

MBC itself makes up 1\% of the breast cancer cases [2, 3], which has increased slightly from $0.86 \%$ over the years $1973-$ 1998 [4]. About 240 men per year will be diagnosed with breast cancer each year in the United Kingdom [3], making it rare, as are tumours in most vestigial organs [5]. $\mathrm{MBC}$ has a higher incidence in the UK and USA as compared with Finland and Japan, although the highest rate $(15 \%$ of all breast cancers seen) was in Zambia [3, 6]. MBC has a uni-modal age distribution peaking in the 6th-7th decade as opposed to the bi-modal distribution seen in women [2, 3, 7]. While studies have suggested men's survival from breast cancer is poorer than women's, when adjustment is made for stage at presentation and age men fare as well or even slightly better $[2,8,9]$. Men tend to present at a later stage of disease [10] and are more likely to undergo mastectomy ( $74 \%$ versus $19 \%$ breastconserving therapy (BCT)) [11]. This tendency to delayed presentation is attributed to lower perceived risk of cancer, symptoms other than a lump, and presentations are often precipitated by an appointment for an unrelated condition or by instruction to seek help by a relative or partner [12].

In terms of treatment, the management of MBC mirrors that of female breast cancer, with surgery and hormonal manipulation being the mainstays [13]. Most publications regarding $\mathrm{MBC}$ bemoan the lack of research into the field, campaign for increase awareness of the disease and attribute the dearth of literature to its rarity [14]. One small American

\section{KARGER}

Fax +497614520714

Information@Karger.com

www.karger.com (c) 2014 S. Karger GmbH, Freiburg

$1661-3791 / 14 / 0091-0029 \$ 39.50 / 0$

Accessible online at:

www.karger.com/brc
Mike Kipling

Breast Unit, University Hospital of North Durham (UHND)

The Barn, East Batter Law Farm

Hawthorn, Seaham, Co Durham, SR7 8RP, UK

mikekipling@doctors.org.uk 
study $(\mathrm{n}=28)$ revealed that $80 \%$ of men attending a breast assessment clinic were unaware that men could develop breast cancer, despite all of them having at least one female blood relative with the disease [15].

\section{Risk Factors for MBC}

The risk factors for MBC are summarised in table 2 [3].

\section{Gynaecomastia}

Whilst a range of conditions make up the clinical caseloads of men referred to a breast clinic [16], a diagnosis of gynaecomastia is most common. As gynaecomastia is more common amongst the obese, we are likely to see the trend of increased referrals continue in coming years [17]. The authors make use of the Braunstein protocol when assessing a patient with gynaecomastia [18]. Treatment can range from simple reassurance or medical therapy through to mastectomy.

\section{Psychological Impact of Breast Assessment and Disease in Women}

Evidence exists for significant psychological morbidity in women with breast disease; the authors postulate that this is likely no different in men. Uncertainty and anxiety is greatest before, but also persists after diagnosis [19] and is universal in breast cancer sufferers $[20,21]$, being greater in those under-

Table 1. Referrals to one of the two breast consultants in Durham (K.C.)

\begin{tabular}{lll}
\hline Year & Men & \% of total referrals \\
\hline 2005 & 29 & 4.0 \\
2006 & 19 & 3.2 \\
2007 & 29 & 3.8 \\
2008 & 28 & 3.7 \\
2009 & 43 & 5.3 \\
2010 & 58 & 7.6 \\
2011 & 54 & 7.4 \\
\hline
\end{tabular}

going mastectomy as opposed to BCT [22]. Screening has also been shown to elicit emotional responses, most commonly anxiety, but also contemplation regarding mortality [23, 24]. The anxiety response is particularly strong if the patient is called for further testing. This anxiety has been shown to persist to some degree even if the diagnosis is ultimately benign [25], and to negatively affect the quality of life and treatment outcome [20], particularly if an anxiety trait is present [26].

Patients are more likely to mount an anxiety response if they have

- multiple medical problems [27],

- trait anxiety as a personality feature [27],

- a higher level of education [27].

- Religion, age and marital status are weakly associated [8].

Factors affecting emotional response to a breast cancer include $[23,28,29]$

- the ability to recognise and express emotions,

- a perceived support network,

- the development of sustained adaptive coping methods as opposed to maladaptive mechanisms such as alcohol intake,

- the ability to manage non-breast disease-related stressors,

- a belief system shifting the meaning of the illness

The first 3 points show why male patients may be particularly vulnerable to psychological distress associated with breast disorders, as they are traditionally regarded as having difficulties in these areas. Alexithymia is the inability to recognise and express emotion; traditionally thought a male characteristic, its incidence is actually equal in both sexes at around $10 \%$ [30]. Also of note is that women provide and receive more emotional support than men, with most men and women seeing female friends/associates as their main source of support [31].

Women with breast cancer are known to have greater difficulty in identifying their feelings regarding their disease and in describing them to others than are healthy women. They often feel loss of control and are significantly less likely to use a problem-solving coping strategy, rather tending to adopt one based on the momentary predominant emotion [30].

Table 2. Risk factors for MBC [3]

\begin{tabular}{ll}
\hline Association & Condition \\
\hline Well-established/strong association & Klinefelter's syndrome (relative risk increased by 50), linked to 3\% of all MBC patients \\
cirrhosis & exogenous oestrogen intake \\
androgen deficiency secondary to testicular disease/damage & BRCA gene carriers \\
& Jewish ethnicity (particularly Ashkenazi Jews) \\
& gynaecomastia \\
& Cowden's syndrome/hereditary nonpolyposis colorectal cancer gene carrier \\
& testicular heat/electromagnetism exposure \\
Poorly established/weak association & high alcohol intake, low socio-economic status \\
& obesity, hypothyroidism \\
pacemakers & tuberculosis \\
&
\end{tabular}




\section{Psychological Impact of Breast Assessment and Disease in Men}

Strength (emotional and physical), muscular development, invulnerability and control are associated with the male psyche in health [31, 32]. Shame, perceived stigma, vulnerability, sadness, anxiety, a sense of unfairness, loneliness and a fear of being marginalised or subordinated within gender hierarchies are all associated with male breast problems, even carriage of the BRCA2 gene [31, 33]. In one study, $43 \%$ of men said they would question their masculinity if diagnosed with $\mathrm{MBC}$ [34], and this sentiment is echoed in publications from around the world [35]. The body image is disturbed for men with breast problems and is even worse for those treated with tamoxifen, due to its psycho-sexual side effects.

Breast development is considered a female trait and can lead to a sense of 'spoiled identity' in men with breast disease [32]. Discussing a problem that is not life threatening or a serious sports injury is considered a weakness by some men [31]. Some studies have linked these uncomfortable emotions to the objectification of women, with the female breast often being viewed by men as an erotic organ without significant alternative function [33].

Most published work regarding the psychological impact of breast disease has focussed on female patients. It must be noted that psychological support is seen as a key feature to managing a female patient with breast cancer, and it is likely that men need no less keen support [36]. In fact, it is known that psychological outcomes are poorer in women undergoing mastectomy versus BCT; men with breast cancer and gynaecomastia, however, are very likely to undergo mastectomy rather than BCT [37]. In studies of men post mastectomy, they report body image disturbance and a reluctance either to bare their chests or even to wear clothing that shows the contour of their chest after mastectomy [38]. Whereas women are likely to actively seek support for their struggle with breast cancer, men are more likely to use concealment or avoidance as a coping strategy. Successful coping strategies for men have included re-assessing or renegotiating their own masculinity [34].

The chronic inhibition of emotion is felt to be a male characteristic that can negatively impact health outcomes. Under extreme circumstances, the hypothalamic-pituitary-adrenal axis can be disturbed, leading to endocrine and emotional dysfunction with development of psychosomatic illness [30]. Headaches, chronic fatigue, obesity and hypertension are consequences of prolonged emotional suppression [20].

The timing of the onset of gynaecomastia has also been shown to be relevant to the outcome, with the greatest psychological impact occurring with onset in adolescence as compared with senescence or young childhood [32]. In a study of 284 adult and adolescent male patients, uncomfortable anxiety regarding masculinity, fear of developing breast cancer, insecurity regarding the psycho-social influence of their breast enlargement prompting the 'reproach of effeminacy', and feeling 'unacceptable' were reported.

Adolescents in this group often stated they thought that their breast enlargement was some fault of their own or that their parents had 'wanted a girl' when they were born. Difficulties with parental relationships were often equated to being rejected due to their 'disfigurement'. These patients universally avoided exposure of their chest, and $68 \%$ of them described some identification with the female sex, developing passive and dependent behaviours. Depressive and even suicidal ideation was common in the studied group, and mainly in those patients with pendulous gynaecomastia.

\section{Assessment of Anxiety}

While breast oncologists detect depression with a sensitivity of $74 \%$, they have low predictive values of when their patients are experiencing psychological distress (30\%) and anxiety $(27 \%)$. A number of standardised assessment tools exist: These vary in their accuracy and may be cumbersome. Based on research into these tools, the literature recommends that a standardised, validated method of assessing anxiety should be used [39]. It remains to be seen which method of assessment is best used, and more research is needed in this area. The authors plan more formalised research into the impact of male breast disease using these tools at a later date.

\section{Management of Psychological Impact of Male Breast Disease}

The 1962 study regarding gynaecomastia in adolescence assessed the response to surgery and psychotherapy, each alone and then in combination [32]. Neither worked on their own to decrease psychological morbidity, but they were efficacious in combination. It must, however, be noted that this study had major methodological flaws, without crossover, blinding or controls. The key features to this therapy were to investigate the significance of the disease to the male patient in question, channel their expression of these feelings, alleviate any feelings of guilt or anxiety and to elevate self esteem. Some of the patients had concerns regarding masculine adequacy predating the development of gynaecomastia, and these were compounded by the condition.

Time constraints, lack of knowledge of screening tools and reluctance to explore upsetting issues with patients are reported barriers to care in this area [20]. Times of particular increase in anxiety include medical information giving, treatment decision-making and scheduling surgery if it is to go ahead, and extra care should be taken around these times with patients both male and female.

Robinson [40] speaks of an 'information divide' in male breast care. Now most women expect to be shown photographs 
of what to expect of the appearance of their post-mastectomy wound, information sheets regarding this and their medical adjuncts. Men have expressed concern that they do not have access to such photographs of male patients and as such were unprepared for their new appearance. When they have had access to literature they also report that it is often female specific, discussing effects on periods, how to fit brassieres, amongst other issues they found uncomfortable. Support programmes are sometimes recommended, although some studies say that these are not helpful and lead to poorer quality of life with a minimised, internal attribution of blame and poorer psychological adjustment [29, 33]. Most men reported that, even if group therapy was offered, they would be unlikely to take it up [40]. Reconceptualising one's image of self and of the disease is also considered a useful coping strategy [33], but more work is needed to determine how to guide this.

The recommendation of the authors is that consideration should be given to the idea that, when attending a breast assessment clinic, men (and women) should undergo assessment with a standardised, validated assessment for psychological morbidity, which will allow targeted therapy and support. Time constraints will mean that a short but effective screening tool must be sought, and the authors propose a role for the distress thermometer as a screening tool [41]. An informal discussion by the specialist breast care nurse may prompt a further discussion of any distress the patient may be experiencing. As male patients mainly rely on female associates for their emotional support, this would make specialist breast care nurses (most commonly women) the ideal group to provide this support.

\section{Survey Methods}

A questionnaire was developed to assess men's opinions regarding the service they received at the breast assessment clinic, their feelings regarding their condition and whether they would like to wait a little longer than they had done to be seen in a male-only clinic. The authors did not make use of the validated tools for this study as it was felt that the questionnaire would become too cumbersome to allow assessment of both this impact and of the clinic service. Instead, free text and direct questions regarding embarrassment were used to assess psychological morbidity. Further planned studies will use a validated tool. Over 18 months, men completed these forms after conclusion of their breast assessment clinic appointment. All men surveyed had benign disease, save one with ductal carcinoma in situ.

\section{Results}

In total, 78 men completed the questionnaires. The results are summarised in table 3 .

\section{Discussion and Conclusion}

Based on this data, men in Durham do not wish to wait longer than they currently do to be seen in a men-only breast assessment clinic. They feel they receive an excellent or good

\begin{tabular}{|c|c|c|}
\hline No. & Question / Answer & Value \\
\hline \multirow[t]{3}{*}{1} & Time from symptoms starting to presentation & \\
\hline & Mean & 6.65 months \\
\hline & Range & 1 day to 15 years \\
\hline 2 & Age range & $18-78$ years \\
\hline \multirow[t]{3}{*}{3} & Embarrassed to see GP & \\
\hline & Yes & $28 \%(\mathrm{n}=22)$ \\
\hline & No & $72 \%(\mathrm{n}=56)$ \\
\hline \multirow[t]{8}{*}{4} & Free text, feelings with GP & \\
\hline & Neutral & $\mathrm{n}=42$ \\
\hline & Anxious & $\mathrm{n}=21$ \\
\hline & Emasculated & $\mathrm{n}=6$ \\
\hline & Stressed/frustrated & $\mathrm{n}=2$ \\
\hline & Depressed & $\mathrm{n}=1$ \\
\hline & Guilty & $\mathrm{n}=2$ \\
\hline & Positive/trusting & $\mathrm{n}=7$ \\
\hline \multirow[t]{3}{*}{5} & Embarrassed in clinic & \\
\hline & Yes & $20 \%(n=16)$ \\
\hline & No & $79 \%(\mathrm{n}=62)$ \\
\hline \multirow[t]{6}{*}{6} & Free text, feelings in clinic & \\
\hline & Neutral & $\mathrm{n}=40$ \\
\hline & Anxious & $\mathrm{n}=25$ \\
\hline & Depressed & $\mathrm{n}=1$ \\
\hline & Awkward & $\mathrm{n}=1$ \\
\hline & Positive/relaxed & $\mathrm{n}=8$ \\
\hline \multirow[t]{3}{*}{7} & Would prefer men-only clinic, with longer wait & \\
\hline & Yes & $0.78 \%\left(\mathrm{n}=1^{\mathrm{a}}\right)$ \\
\hline & No & $99 \%(\mathrm{n}=77)$ \\
\hline \multirow[t]{3}{*}{8} & Overall clinic service & \\
\hline & Excellent & $78 \%(\mathrm{n}=61)$ \\
\hline & Good & $22 \%(\mathrm{n}=17)$ \\
\hline
\end{tabular}

32

Breast Care 2014;9:29-33
Table 3. Questionnaire (free text and direct questions) regarding embarrassment to assess psychological morbidity 
service as it is currently run. Even a crude tool such as the one used has elicited significant psychological morbidity amongst some patients presenting at the clinic, and as such further research using validated tools is indicated: The current tool picks up embarrassment as it is directly asked about, but likely misses some of the subtle findings that a formalised tool would pick up. Future work in the unit will explore this in more depth, and the authors recognise the flaws in this study. Fewer men were embarrassed to come to the clinic than had been embarrassed to attend their general practitioner (GP). It is likely that the GP validated these men's concerns and empowered them to seek further assessment. The awareness of health professionals regarding male breast problems is key to improving management, and tailoring a service to men with breast problems must be a part of the development of a modern breast service.

\section{Disclosure Statement}

The authors report no conflict of interest and received no funding for this work.

\section{References}

1 Al-Allak A, Govindarajulu S, Shere M, Ibrahim N, Sahu AK, Cawthorn SJ: Gynaecomastia: a decade of experience. Surgeon 2011;9: 255-258.

2 Miao H, Verkooijen HM, Chia KS, et al.: Incidence and outcome of male breast cancer: an international population-based study. J Clin Oncol 2011;29: $4381-4386$.

3 Contractor KB, Kaur K, Rodrigues GS, Kulkarni DM, Singhal H: Male breast cancer: is the scenario changing? World J Surg Oncol 2008;6:58.

4 Giordano SH, Cohen DS, Buzdar AU, Perkins G, Hortobagyi GN: Breast carcinoma in men: a population based study. Cancer 2004;101:51-57.

5 Barh D: Biomarkers, critical disease pathways, drug targets, and alternative medicine in male breast cancer. Curr Drug Targets 2009;10:1-8.

$\checkmark 6$ Ewertz M: Epidemiology of breast cancer: the Nordic contribution. Eur J Surg 1996;162:97-99.

7 Weiss JR, Moysich KB, Swede H: Epidemiology of male breast cancer. Cancer Epidemiol Biomarkers Prev 2005;14:20-26.

8 Bölükbaș N, Erbil N, Kahraman AN: Determination of the anxiety level of women who present for mammography. Asian Pac J Cancer Prev 2010;11: 495-498.

9 Marchal F, Salou M, Marchal C, Lesur A, Desandes $\mathrm{E}$ : Men with breast cancer have same disease-specific and event-free survival as women. Ann Surg Oncol 2009;16:972-978.

10 Ravi A, Bang H, Karsif K, Nori D: Breast cancer in men: prognostic factors, treatment patterns, and outcome. Am J Mens Health 2012;6:51-58.

11 Tallon-Aguilar L, Serrano-Borrero I, Lopez-Porras M, Sousa-Vaquero JM: Breast cancer in males. Cir Cir 2011;79:296-298.

12 Gould J, Fitzgerald B, Fergus K, Clemons M, Baig F: Why women delay seeking assistance for locally advanced breast cancer. Can Oncol Nurs J 2010; 20:23-29.

13 Giordano SH: A review of the diagnosis and management of male breast cancer. Oncologist 2005;10:471-479.

14 Kiluk JV, Lee MC, Park CK, et al.: Male breast cancer: management and follow-up recommendations. Breast J 2011;17:503-509.

15 Thomas E: Original research: men's awareness and knowledge of male breast cancer. Am J Nurs 2010;110:32-37.
6 Iuanow E, Kettler M, Slanetz PJ: Spectrum of disease in the male breast. AJR Am J Roentgenol 2011;196:W247-W259.

17 Alali L, Honarpisheh H, Shaaban A, Speirs V: Conditions of the male breast: gynaecomastia and male breast cancer (review). Mol Med Rep 2010; 3:21-26.

18 Braunstein GD: Gynecomastia. N Engl J Med 2007;357:1229-1371.

19 Liao MN, Chen MF, Chen SC, Chen PL: Uncertainty and anxiety during the diagnostic period for women with suspected breast cancer. Cancer Nurs 2008;31:274-283.

20 Pedersen AE, Sawatzky JA, Hack TF: The sequelae of anxiety in breast cancer: a human response to illness model. Oncol Nurs Forum 2010;37:469475.

21 Montgomery M: Uncertainty during breast diagnostic evaluation: state of the science. Oncol Nurs Forum 2010;37:77-83.

22 Lim CC, Devi MK, Ang E: Anxiety in women with breast cancer undergoing treatment: a systematic review. Int J Evid Based Healthc 2011;9:215-235.

23 Blow AJ, Swiecicki P, Haan P, et al.: The emotional journey of women experiencing a breast abnormality. Qual Health Res 2011;21:1316-1334.

24 Taha SA, Matheson K, Paquet L, Verma S, Anisman H: Trust in physician in relation to blame, regret, and depressive symptoms among women with breast cancer experience. J Psychosoc Oncol 2011;29:415-429.

25 Van der Steeg AFW, Keyzer-Dekker CMG, De Vries J, Roukema JA: Effects of abnormal screening mammogram on quality of life. Br J Surg 2011; 98:537-542.

26 Van der Steeg AFW, De Vries J, Roukema JA: Anxious personality and breast cancer: possible negative impact on quality of life after breast-conserving therapy. World J Surg 2010;34:1453-1460.

27 Montgomery M, McCrone SH: Psychological distress associated with the diagnostic phase for suspected breast cancer: systematic review. J Adv Nurs 2010;66:2372-2390.

28 Kinsinger SW, McGregor BA, Bowen DJ: Perceived breast cancer risk, social support, and distress among a community-based sample of women. J Psychosoc Oncol 2009;27:230-247.
29 Cousson-Gelie F, Bruchon-Schweitzer M, Atzeni T, Houede N: Evaluation of a psychosocial intervention on social support, perceived control, coping strategies, emotional distress, and quality of life of breast cancer patients. Psychol Rep 2011;108: 923-942.

30 Manna G, Foddai E, Di Maggio MG, et al.: Emotional expression and coping style in female breast cancer. Ann Oncol 2007;18(suppl 6):vi77-vi80.

31 Stromsvik N, Raheim M, Oyen N, Engebretsen LF, Gjengedal E: Stigmatization and male identity: Norwegian males' experience after identification as BRCA1/2 mutation carriers. J Genet Counsel 2010; 19:360-370.

32 Schonfeld WA: Gynecomastia in adolescence: effect on body image and personality adaptation. Psychosom Med 1962;4:379-389.

33 Wassersug RJ, Oliffe JL: The social context for psychological distress from iatrogenic gynaecomastia with suggestions for its management. J Sex Med 2009;6:989-1000.

34 Donovan T, Flynn M: What makes a man a man? The lived experience of male breast cancer. Can Nurs 2007;30:464-470.

35 Yaghan RJ, Bani-Hani KE: Male breast disorders in Jordan. Disease patterns and management problems. Saudi Med J 2004;25:1877-1883.

36 Nilsson C, Holmqvist M, Bergkvist L, Hedenfalk I, Lambe M, Fallskog ML: Acta Oncol 2011;50:10831088.

37 Lanitis S, Rice AJ, Vaughan A, et al.: Diagnosis and management of male breast cancer. World J Surg 2008;32:2471-2476.

38 France L, Michie S, Barrett-Lee P, Brain K, Harper P, Gray J: Male cancer: a qualitative study of male breast cancer. Breast 2000;9:343-348.

39 Okuyama T, Akechi T, Yamashita H, et al.: Oncologists' recognition of supportive careneeds and symptoms of their patients in a breast cancer outpatient consultation. Jpn J Clin Oncol 2011;41: 1251-1258.

40 Robinson JD, Metoyer KP Jr, Bhayani N: Breast cancer in men: a need for psychological intervention. J Clin Psychol Med Settings 2008;15:134-139.

41 Carlson LE, Groff SL, Maciejewski O, Bultz BD: Screening for distress in lung and breast cancer outpatients: a randomized controlled trial. J Clin Oncol 2010;28:4884-4891. 